\title{
Efficacy of Yoga on pregnancy outcome, J Altern Complement Med. 2005 Apr;11(2):237-44
}

\author{
Pooja Nadholta \\ Neuroscience Research Lab, Department of Neurology, PGIMER, Chandigarh, India.
}

Pooja Nadholta

Neuroscience Research Lab

Department of Neurology

PGIMER, Chandigarh, India

Contact no: +91-8988166700

E-mail: nadholtapooja34@gmail.com

\section{Introduction}

Pregnancy is a unique and challenging state, both physically and mentally. This requires mental, physical and social adaptation. Pregnancy related complications like pregnancy induced hypertension, preeclampsia, physiological and psychological stress, impaired placentation directly affect the fetal growth and also health of the neonate. It is already shown by animal experimentation that pregnancy outcomes are directly affected by prenatal maternal stress and it results in early programming of various organ systems that permanently changes neuroendocrine regulation and behavior in offspring (1). Various life events, illness, divorce, financial and social problems are some of the common stressor during pregnancy that activates hypothalamus-pituitaryadrenal cortex system (HPA axis) and sympathetic nervous system-adrenal medulla system (stress regulation system). Physical alteration, hormonal changes and anxiety are common during pregnancy period and these worsen the stress response. Already various attempts have been made to reduce pregnancy related stress (2,3). A study demonstrated that Yoga can be an effective therapy in reducing the pregnancy related complications and improving fetal outcomes (4). Satyapriya et al.showed that Yoga reduces anxiety, depression and pregnancy related uncomfortable experiences (5). Meditations inhibit the HPA axis that is activated during stress and calms the mind. Yoga is used to promote positive health and it uses holistic approach to reduce the stress. Integrated approach of Yoga therapy (IAYT) helps in reducing stress by practicing different postures (asanas), slow controlled breathing (Pranayama), Meditation and Chanting. This study tests the effect of IAYT on pregnancy related complications, stress and pregnancy outcome.

\section{Study design}

335 pregnant women from antenatal care at Gunasheela Surgical and Maternity Hospital Bangalore, India were included in the study. Pregnant women were enrolled in a prospective observational study between January 2000 and December 2002.
Total 3500 women were screened and out of them 1200 fit the eligibility criteria. These 1200 women were divided into far group ( $\mathrm{n}=438,15$ minutes from hospital) and near group ( $n=762$, further than 15 minutes). At the end 166 women in control group and 169 in Yoga group (total 335) agreed to be the part of the study by giving their signature on Informed Consent Form. Women aged between 18 to 35 years with normal health condition and no Yoga training before were included and those with multiple pregnancies, complicated medical illness, intrauterine infections and previous pregnancy loss due to any genetic defect were excluded from study. Yoga group practiced Yoga (IAYT) taught by well trained Yoga therapist including physical postures (asanas), breathing (pranayam) and meditation from the date of entry in the study until delivery. Control group walked twice a day for half an hour during study period. Blood pressure, ultra sound scan and Doppler during routine antenatal visit. At the time of birth, the mode of delivery, gestational age, and birth weight were examined. Considerably positive results were observed in Yoga group than control group. Statistical analysis was done using the SPSS statistical software.

\section{Implications}

Maternal characteristics remained same in both Yoga and control group before and after the intervention. In intervention group there was significant decrease in preterm deliveries, decreased numbers of small-for-gestational-age babies, and decreased incidence of idiopathic IUGR and PIH. Hence, it can be concluded that Yoga is a safe and effective intervention during pregnancy and increases pregnancy outcome. An integrated approach to Yoga during pregnancy is safe. It improves birth weight, decreases preterm labor, and decreases IUGR with no increased complications

Received Date: 09-02-20; Revised Date: 11-02-20 Accepted Date: 13-02-20

\section{References}

1. Mulder EJ, De Medina PR, Huizink AC, Van den Bergh BR, Buitelaar JK, Visser GH. Prenatal maternal stress: effects on pregnancy and 
the (unborn) child. Early human development. 2002 Dec 1;70 (1-2):3-14.

2. Fenster L, Schaefer C, Mathur A, Hiatt RA, Pieper C, Hubbard AE, Von Behren J, Swan SH. Psychologic stress in the workplace and spontaneous abortion. American Journal of Epidemiology. 1995 Dec 1;142(11):1176-83.

3. Villar J, Farnot U, Barros F, Victora C, Langer A, Belizan JM. A randomized trial of psychosocial support during high-risk pregnancies. New England Journal of Medicine. 1992 Oct 29;327(18):1266-71.
4.

Rakhshani A, Nagarathna R, Mhaskar R, Mhaskar A, Thomas A, Gunasheela $\mathrm{S}$. The effects of yoga in prevention of pregnancy complications in high-risk pregnancies: a randomized controlled trial. Preventive medicine. 2012 Oct 1;55(4):333-40.

5. Rakhshani A, Nagarathna R, Mhaskar R, Mhaskar A, Thomas A, Gunasheela $S$. The effects of yoga in prevention of pregnancy complications in high-risk pregnancies: a randomized controlled trial. Preventive medicine. 2012 Oct 1;55(4):333-40.

doi: $10.38205 /$ imcr.010137 